\title{
Advances in Diagnostics of Parasitic Diseases: Current Trends and Future Prospects
}

\author{
Rupesh Verma ${ }^{1}$, G. Das ${ }^{2 *}$, H. V. Manjunathachar ${ }^{3}$ and Nirmala Muwel $^{1}$ \\ ${ }^{I}$ Veterinary Assistant Surgeon, Department of Animal Husbandry, Mandsaur \\ (M.P)-458001, India \\ ${ }^{2}$ Department of Veterinary Parasitology, College of Veterinary Science \& AH, Jabalpur \\ (MP)-482001, India \\ ${ }^{3}$ Division of Virology and Zoonotic diseases, ICMR-National Institute for Research in Tribal \\ Health (NIRTH), Jabalpur (MP)-482003, India \\ *Corresponding author
}

\section{A B S T R A C T}

\begin{tabular}{|l|}
\hline Ke y w or d s \\
$\begin{array}{l}\text { Parasitology, genomics, } \\
\text { Serological, Molecular } \\
\text { techniques, OMICS } \\
\text { technologies }\end{array}$ \\
\hline Article Info \\
\hline $\begin{array}{l}\text { Accepted: } \\
\text { 24 June } 2018 \\
\text { Available Online: } \\
\text { 10 July } 2018\end{array}$ \\
\hline
\end{tabular}

\begin{abstract}
Parasitic diseases constitute a major group of chronic infectious diseases in livestock and jeopardize animal health results in poor production. However, treatment and control of diseases are largely dependent on timely diagnosis. Usually, the diagnosis of parasitic infections relies on testing for the presence of parasites through direct faecal examination, blood smear, lymph node biopsy etc, but clinically, it is often difficult to elucidate the entire offending organism. Accurate diagnoses of parasitic infections are always a prerequisite for successful treatment and control of animal diseases. Besides, the rapid development of drug resistance against anti-parasitic drugs urges the need for the development of the alternative, early diagnostic techniques. In modern years, research has been focused towards alternative methods to improve the diagnosis of parasitic diseases. In this paper, we reviewed the application of various diagnostic techniques for the detection of parasitic infections currently in use and future developments.
\end{abstract}

\section{Introduction}

Livestock sector plays a pivotal role in improving the socio-economic conditions of developing countries. In India, livestock sector contributes $4.11 \%$ of GDP and more than one fourth $(25.6 \%)$ total output of the agricultural sector GDP (Livestock census, 2012). Among infectious diseases, parasites are a major cause of production loss in terms of morbidity and mortality, results in significant economic losses and its impact directly on the livelihood of farmers. The global loss due to ticks and tick-borne diseases (TTBDs) was estimated to be between the US \$13.9 and 18.7 billion annually while in India the cost of controlling TTBDs has been estimated at the US \$ 498.7 million/annum (De Castro, 1997; Minjauw and McLeod, 2003).

In India, tick-borne diseases in animals, like theileriosis and babesiosis causes economic loss to the tune of US $\$ 800$ million and the US \$ 67.2 million, respectively, per annum 
(Devendra, 1995; Montenegro et al., 1998). So, to formulate effective treatment and control strategies against parasitic diseases, specific diagnosis of parasites is essential to know the true status of parasitic diseases in animals of a particular region. Since the introduction of light microscopy, morphological identification of parasites has been the cornerstone of routine laboratory diagnosis in Parasitology.

However, the sensitivity of identifying parasites to occult or acute infection is less. Further, serology based diagnosis is not specific in all the cases. So, currently, to address these issues, nucleic-acid based methods have been employed to detect parasites responsible for parasitic diseases. In the present review, we addressed different serological and molecular techniques employed for diagnosis of different parasitic diseases of animals.

\section{Microscopy-based method}

Microscopy-based detection methods are economically cheaper and considered the gold standard for diagnosis of parasitic infections. However, due to limitations such as technical expertise, occult/ acute infection status of animal etc. may reduce the sensitivity of this test.

\section{Serology based methods}

Serology tests are considered as the gold standard when biologic samples or tissue specimens are not available for diagnosis. It can be divided into two categories: antigendetection and antibody-detection assays.

Serology based method requires considerable skill, time-consuming and labour-intensive in nature. Some tests which are routinely used for parasite detection are addressed (Table no $1)$.

\section{Complement fixation test}

The Complement fixation test is one of the most widely applicable serologic techniques. Once the required reagents, antigen, complement, sheep erythrocytes and antibody against erythrocytes are prepared and standardized, the complement fixation test used for detection of trypanosomosis, helminthosis, anaplasmosis, babesiosis and toxoplasmosis (Ndao, 2009; Deepak and Singla, 2016). Based on this test, a commercial kit (COFEB Kit) has been developed for the diagnosis of equine piroplasmosis (Sengupta, 2004). Complement fixation test screens a large number of samples at a time and can be automated with relatively simple and inexpensive equipment. It shows increased specificity with a reproducible result. Limitation of this test is not much sensitive and cannot be used for immunity screening, time consuming and labour intensive assay. Non-specific binding of complement may produce false positive results.

\section{Latex agglutination test}

Latex agglutination is observed when a sample containing the specific antigen (or antibody) is mixed with an antibody (or antigen) which is coated on the surface of latex particles. This test has been used for diagnosis of Fasciola spp. Trichinella spiralis, Babesia bigemina, and Toxoplasma gondii (Ndao, 2009; Deepak and Singla, 2016). Card agglutination for trypanosomosis tests (CATT) was originally developed for the diagnosis of Trypanosoma gambiense gambiense later on for T. evansi (Surratex based on trypanosome- antigen detection in blood or serum) infection in livestock using latex beads coated with native RoTat 1.2 (Songa and Hamers, 1988). Recently, the N-terminal fragment of VSG RoTat 1.2 has been expressed as a recombinant protein in the yeast Pichia 
pastoris and incorporated in a latex agglutination test, the rLATEX/T. evansi (Roge et al., 2014).

\section{Indirect fluorescent antibody test}

Indirect fluorescent antibody test may be used for the detection of antibodies in serum or for the demonstration and identification of antigens in tissues or cell cultures. This test has been applied to the detection of theileriosis, helminthosis, anaplasmosis, besnoitiosis, ehrlichiosis/ malaria, babesiosis, trypanosomosis, toxoplasmosis (Ndao, 2009; Deepak and Singla, 2016). This test is fast, relatively cheap, easy to detect and highly sensitive and specific. This test used on pathogens that can't be easily cultured and allows viewing of labeled cells in a natural environment. The disadvantage of this test is the potential for cross-reactivity and the need to find primary antibodies that are not raised in same species or different isotypes.

\section{Radioimmunoassay}

In radioimmunoassay, radioisotopes are used to measure the immune complex formed by the combination of antigen and antibody. This test used for detection of Babesia bovis and Trypanosoma congolense (Ricciardi and Ndao, 2015; Ranjan et al., 2015). This test is highly specific and sensitivity. Radiolabeled reagents produce severe radiation hazards. The demerits of the test are requires special laboratory, trained staff to handle radioactive material and requires special arrangements for storage and disposal of radioactive material.

\section{Enzyme-linked immunosorbent (ELISA)}

Enzyme-linked immunosorbent assay (ELISA) is a method of quantifying an antigen immobilized on a solid surface. In this test uses a specific antibody with a covalently coupled enzyme. ELISA test has been applied for the detection of babesiosis, besnoitiosis, helminthosis, toxoplasmosis, trypanosomosis anaplasmosis, and ehrlichiosis (Ricciardi and Ndao, 2015; Ranjan et al., 2015).

The first commercial ELISA kit for the diagnosis of Theileria annulata infection in cattle based on a recombinant protein known as $T$. annulata surface protein (TaSp-1) and named as SVANOVIR (Al-Hosary et al., 2015).

\section{Dot-ELISA}

This is a simple and filed oriented test where, the plastic well are replaced by a nitrocellulose or other paper membrane. In this method, small amount of sample will be dotted and incubated with an antigen-specific antibody followed by an enzyme-conjugated anti-antibody.

A coloured dot is formed on the membrane on the addition of chromogenic substrate indicates the positive result. Several studies have demonstrated the usefulness of the study in detection of the parasitic infection caused by Fasciola gigantica, Haemonchus contortus, Theileria equi, Trypanosoma cruzi, and Trypanosoma brucei in different livestock species (Ranjan et al., 2015; Deepak and Singla, 2016).

\section{Luciferase Immunoprecipitation System (LIPS)}

This is a unique modified version of ELISAbased assay where specific antigen - antibody response will be identified by measuring light production. Presently, test was used to detect Strongyloides stercoralis (using a Ruc-NIE fusion) and Loa loa (using a Ruc-LISXP-1 fusion) infection by specific antigen -antibody interaction (Ramanathan et al., 2008; Burbelo et al., 2008). 


\section{Immunochromatographic assays}

Immunochromatography is a combination of chromatography (separation of components of a sample based on differences in their movement through a sorbent) and immunochemical reactions. The immunochromatography method is almost similar to Sandwich ELISA method where the only difference is that immunological reaction is carried out on the chromatographic paper by capillary action rather on plastic wells. For this system, two kinds of specific antibodies against antigen are used. One of the antibodies is immobilized on the chromatographic paper and the other is labeled with colloidal gold and infiltrated into sample pad. An immunochromatographic unit is completed by attaching the sample pad at the end of the membrane. In the last decade, many immunochromatography tests have been developed using recombinant antigens such as rEMA2 and recombinant Babesia caballi 48$\mathrm{kDa}$ rhoptry protein $((\mathrm{rBc} 48)$ for $T$. equi and B. caballi infections in equine, respectively (Huang et al., 2004; Cruz-Flores et al., 2010). In cattle, some immunochromatography tests, developed using recombinant antigens are recombinant merozoite surface antigen-2 (rMSA-2), spherical body protein-4 (SBP-4), rhoptry-associated protein 1 (RAP-1) and Theileria annulata (TaSP-1) antigen for Babesia bovis, Babesia bigemina and $T$. annulata infections, respectively (Kim et al., 2008; Guswanto et al., 2017). In dog P50 antigen and BgSA1 are for Babesia gibsoni infections (Verdida et al., 2005; Jia et al., 2007). In order to diagnose Trypanosoma evansi infection in domestic animals, a recombinant variant surface glycoprotein (rVSG) RoTat 1.2 expressed in yeast $P$. pastoris was used and named the test as Surra Sero K-SeT test. The overall sensitivity of the Surra Sero K-SeT was higher when compared with CATT/T. evansi. Hence this may become an alternative for the CATT/T. evansi for sensitive detection of antibodies against $T$. evansi in domestic animals (Birhanu et al., 2015). Currently, lateral flow test (LFA) has been used for the identification of sera sample infected with $T$. evansi in equine. The test was compared with ELISA; it was observed that $93.31 \%$ sensitive and $100 \%$ specific, as none of the negative field sample, was found positive in LFA (Yadav, 2018).

\section{Molecular-Based methods}

The use of DNA/RNA based methods derives from the premise that each species of parasite carries unique DNA or RNA sequences that differentiate it from other parasites. The molecular technique with the widest variety and application in parasitology diagnostics is PCR. Apart from the conventional PCR (nested and multiplexed PCR), recently realtime PCR is also using for the detection of several parasitic infections. Newer technologies such as random amplified polymorphic DNA (RAPD), microsatellite marker, loop-mediated isothermal amplification, Luminex based assays, nanotechnology, and biosensor have also emerged as possible new approaches for the diagnosis of parasitic diseases.

\section{Polymerase Chain Reaction (PCR)}

PCR having exquisite sensitivity and specificity for the detection of nucleic acid targets and become one of the most important diagnostic tools in parasitology (Gasser et al., 2006). The PCR is used for the accurate identification of parasites and their genetic characterization, diagnosis of parasitic infections as a differential diagnosis, the isolation and characterization of expressed genes detection of anthelmintic resistance and identification of involved genes in mutation. The genetic markers like 18 sRNA, ITS- 1 and ITS-2 are routinely used for identification of Amphistomes (Lofty et al., 2010), Fasciola 
(Alba et al., 2015) and coccidia species (Gadelhaq et al., 2015). Eimeria ninakohlyakimovae and E. christenseni infections in Indian goats using 18S rRNA and ITS-1 genes have been genetically characterized using PCR based molecular techniques (Verma et al., 2017).

\section{Real-Time Polymerase Chain Reaction (RT-PCR)}

RT- PCR is the latest improvement in the standard PCR technique used in parasitology laboratories. The fluorescence readings are plotted by computer software and results can be transmitted electronically, eliminating the needof post-PCR reaction analysis by electrophoresis and reducing time.

The RT- PCR assay provides quantification of the sample using several fluorescent dyes such as TaqMan probes, SYBR Green dye and Scorpion primers (Ricciardi and Ndao, 2015). Several studies have been conducted on the application of SYBR Green I RT-PCR to protozoans viz., Cryptosporidium, Leishmania, Trypanosoma, Giardia and T. gondii (Tavares et al., 2011).

\section{Nucleic acid sequence-based amplification (NASBA)}

NASBA is a promising gene amplification method involves two-step process where, there is an initial enzymatic amplification of the nucleic acid targets followed by detection of the generated amplicons. The entire NASBA process is conducted at a single temperature, thereby eliminating the need of thermocycler. Recently, NASBA has been used for diagnosis of Babesia and Theileria using RNA as an initial template (Skotarczak and Sawczuk, 2008) and also used in combination with gold nanorods to develop a colorimetric assay targeting the 18S rRNA of Leishmania spp (Niazi et al., 2013).

\section{Loop-Mediated Isothermal Amplification (LAMP)}

LAMP is a simple, rapid, specific and costeffective single tube technique for the amplification of target genes. Amplification and detection of gene can be completed in a single step in shorter duration (15-60 minutes) by incubating the mixture of samples, primers, Bst DNA polymerase with strand displacement activity and substrates at a constant temperature (about $60-65^{\circ} \mathrm{C}$ ). The LAMP having several advantages over other nucleic acid detection test. Since, it is a isothermal nucleic acid amplification technique and no need of expensive thermal cyclers and no need of post-PCR analysis of samples. The LAMP test have been used to detect several parasitic diseases, viz., Cryptosporidium spp, E. histolytica, Plasmodium spp, Trypanosoma spp, Taenia spp, Schistosoma spp, Fasciola hepatica, F. gigantica, T. gondii Theileria, Babesia and Eimeria (Alhassan et al., 2007; Guan et al., 2008; Ranjan et al., 2015; Barkway et al., 2015). Further, it is used for identification of parasites in their vectors such as Dirofilaria immitis in mosquitoes miracidium after the first day of exposure in snails, the intermediate hosts of Schistosoma (Aonuma et al., 2009; Abbasi et al., 2010).

\section{Luminex xMAP Technology}

Luminex is a bead-based xMAP technology (multianalyte profiling), a system that combines flow cytometry, fluorescent microspheres (beads), lasers and digital signal processing. Technology having advantages like, simultaneously measuring up to 100 different analytes in a single sample. In diagnostic parasitology, this technology is still new, but it has been used to diagnose $E$. histolytica, Giardia, Cryptosporidium, Ascaris, Necator, Ancylostoma, Strongyloides, T. gondii, Toxocara canis, T. cati, and $T$. 
spiralis (Ndao, 2009; Ranjan et al., 2015; Reslova et al., 2017).

\section{Random Amplified Polymorphic DNA (RAPD)}

This technique is also known as arbitrarily primed PCR. Test is based on amplification of genomic DNA with a single primer selected from an arbitrary nucleotide sequence. RAPD has been extensively used for description of strains in epidemiological studies. The RAPD is a very simple, fast and inexpensive technique that does not require either prior knowledge of the DNA sequence or DNA hybridization. Generally, this method used to differentiate species of Leishmania, in addition to polymorphisms studies of parasites such as Plasmodium, Trypanosoma, E. granulosus and $T$. solium and $W$. bancrofti (Tavares et al., 2011; Ranjan et al., 2015).

\section{Amplified Fragment Length Polymorphism (AFLP)}

AFLP is the selective amplification of restriction fragments from a digest of total genomic DNA using the polymerase chain reaction (PCR). AFLP has been successfully applied to differentiate isolates of $C$. parvum into two distinct genotypes, as well as strains of Leishmania belonging to cutaneous leishmaniosis and visceral leishmaniosis (Blears et al., 2000; Kumar et al., 2010).

\section{Restriction Fragment Length Polymorphism (RFLP)}

RFLP is majorly used to differentiate organisms based on thepatterns derived after enzymatic cleavage of their DNA. Based on the cleavage of a particular restriction endonuclease, the length of the fragments will be produced. The cleavage patterns generated after enzymatic digestion will be used to differentiate species (and even strains) from one another. The RFLP technique is commonly used for diagnosis of species and genotypes of parasites such as T. gondii, Cryptosporidium spp. and Theileria spp. (Quan et al., 2008; Molloy et al., 2010; Zaeemi et al., 2011). Recently, semi-nested PCR-RFLP was used for detection of persistent anaplasmosis (Jaswal et al., 2014).

\section{Microarray technology}

Microarray is one of the most recent methodbeing used in veterinary research. Originally developed for the mapping of genes and being used to detect a wide variety of veterinary pathogens. It is based on the base pairing matching of known and unknown DNA samples with array of coated samples.

This is a combination of DNA amplification with subsequent hybridization to oligonucleotide probes specific for multiple target sequences. It allows analysis of a larger number of genetic features in a single trial. It has been used in detection and genotyping of Plasmodium, Toxoplasma and Trypanosoma spp (Duncan et al., 2004).

\section{Microsatellites}

Microsatellites are the short DNA sequences consist of tandem repeats of one to six nucleotides with approximately one hundred repeats. Microsatellites are used due to frequent polymorphism, co-dominant inheritance, high reproducibility and high resolution of the genes in both identification and diagnosis of some parasites of both humans and animals.

Despite their potential usefulness, microsatellite markers were developed only for few parasites such as species of Trichostrongyloid nematodes and T.gondii (Temperley et al., 2009; Ajzenberg et al., 2010) 


\section{Nanotechnology}

Nanotechnology is the study of extremely small structures, having size of 0.1 to $100 \mathrm{~nm}$. With the help of nanomedicine early detection and prevention, improved diagnosis, proper treatment and follow up of diseases are possible. Certain nanoscale particles are used as tags and labels, biological can be performed quickly, the testing has become more sensitive and more flexible. A small number of parasites have been the target for nanotechnology, focusing primarily in Leishmania sp. and Plasmodium sp. (De Carvalho et al., 2013; Waknine-Grinberg et al., 2013). Currently, researches are going on using nanopeptides against Haemonchus contortus and Fasciola hepatica in Cuba and Brazil.

\section{Biosensing technology}

A biosensor mainly consists of two components such as bioreceptor and a transducer. The bioreceptor will recognizes the target analyte whereas, the transducer converts the recognition event into a measurable signal. In parasitological point of view, a low-cost biosensor system was made with nanostructure films containing specific $L$. amazonensis and $T$. cruzi antigens and employing impedance spectroscopy as the detection method (Perinoto et al., 2010). Over the long term, we believe that biosensor technology combining nanotechnologies, advance nucleic acid amplification methods and next-generation sequencing analysis will be a powerful systemic tool for pathogens detection and surveillance system to control animal disease outbreaks and prevention (Wang, 2005; Vidic et al., 2017).

\section{Application of high throughput 'omics' technologies in veterinary parasitology}

The advent and integration of high-throughput '-omics' technologies (e.g. genomics, transcriptomics, proteomics, metabolomics, glycomics and lipidomics) are revolutionizing the science and allowing the systems biology of organisms to be explored. These technologies are now providing unique opportunities for molecular, genetic, hostparasitic interaction, diagnosis, development of drugs and vaccine molecule identification against parasitic diseases (Cantacessi et al., 2012; Cantacessi et al., 2012).

\section{High throughput sequencing (HTS)}

Whole genome sequencing started with the sequencing of a bacteriophage in 1977 using the Sanger sequencing technique. In the last few years, it has become possible to sequence the whole genome of key parasites and related organisms, such as Caenorhabditis elegans (Brenner, 1974). In fact, the genome of this nematode was first completed genome for any multi-cellular organism and helped in development of resource for research on helminths. These breakthrough platforms have rapidly evolved from next-generation sequencing (NGS) or second-generation platforms [454 / Roche sequencing, Illumina (Solexa) sequencing, SOLiD systems and Ion Torrent sequencing)] to third-generation [PacBio RS II (Pacific Biosciences) and Heliscope sequencer (Helicos BioScience)] and fourth-generation sequencing machines [MinION (Oxford Nanopore)]. HTS technologies are now providing the opportunity to detection, identification, characterization of previously unidentified parasites, molecular marker profiles, whole genome sequencing and pathotyping or resistance typing information. Sequencing, mapping and comparing the genomes of cells in healthy and disease states, cheaply, rapidly and accurately can alter the way clinicians think about how to treat patients shifting from traditional medicine to a genome based era of preventive and therapeutic decisions ( $\mathrm{Ku}$ and Roukos, 2013; Belák et al., 2013). 
Table.1 OIE recommended test for the international trade of animal and its products (OIE, 2008)

\begin{tabular}{|c|c|c|c|}
\hline S. No. & Disease name & Prescribed tests & Alternative tests \\
\hline 1. & Trichinellosis & Agent identification & Enzyme-linked immunosorbent assay \\
\hline 2. & Trichomonosis & Agent identification & Mucus agglutination test \\
\hline 3. & Dourine & Complement fixation & $\begin{array}{l}\text { Enzyme-linked immunosorbent assay, Indirect } \\
\text { fluorescent antibody }\end{array}$ \\
\hline 4. & Equine piroplasmosis & $\begin{array}{l}\text { Enzyme-linked } \\
\text { immunosorbent assay, } \\
\text { Indirect fluorescent antibody }\end{array}$ & Complement fixation \\
\hline 5. & Theileriosis & $\begin{array}{l}\text { Agent identification, Indirect } \\
\text { fluorescent antibody }\end{array}$ & - \\
\hline 6. & $\begin{array}{l}\text { Trypanosoma evansi } \\
\text { infection }\end{array}$ & Card agglutination tests & - \\
\hline 7. & Bovine anaplasmosis & - & Card agglutination test, Complement fixation \\
\hline 8. & Bovine babesiosis & - & $\begin{array}{l}\text { Enzyme-linked immunosorbent assay, Indirect } \\
\text { fluorescent antibody, Complement fixation }\end{array}$ \\
\hline 9. & Bovine anaplasmosis & - & Card agglutination test, Complement fixation \\
\hline 10. & Bovine babesiosis & - & $\begin{array}{l}\text { Enzyme-linked immunosorbent assay, Indirect } \\
\text { fluorescent antibody, Complement fixation }\end{array}$ \\
\hline 11. & $\begin{array}{l}\text { Trypanosomosis } \\
\text { (Tsetse-transmitted) }\end{array}$ & - & Indirect fluorescent antibody \\
\hline 12. & Mange & - & Agent identification \\
\hline
\end{tabular}

In the last years, numerous studies have demonstrated the utility of NGS technologies for population genetics and molecular biology of parasites including strongylid nematodes, whitefly, ticks, Giardia intestinalis, Trichomonas vaginalis, Cryptosporidium and Toxocara (Chen et al., 2009; Wang et al., 2010; Cantacessi et al., 2012; Gasser, 2013; Qablan et al., 2014; Zahedi et al., 2017).

\section{Bioinformatics}

Bioinformatics comprises mathematical approaches and algorithms applied to biology and medicine using Information Technology tools, e.g. databases and mining softwares. Analysis of omics data typically follows four steps: (1) data processing and identification of molecules, (2) statistical data analysis, (3) pathway and network analysis, and (4) system modeling. Examples include de novo genome assembly, genome annotation, identification of co- or differentially expressed genes at the level of transcripts or proteins and the inference of protein- protein interaction networks (Ballereau et al., 2013). Recent studies have utilized bioinformatics platform to explore the complement of molecules transcribed in different developmental stages and both sexes of key parasitic nematodes, including $T$. columbriformis (Cantacessi et al., 2010) H. contortus (Cantacessi et al., 2010), Necator americanums (Cantacessi et al., 2010) and Oesophagostomum dentatum (Lin et al., 2012). Accurate bioinformatics analyses of transcriptomic and genomic data are crucial for providing meaningful biological information on parasites. Until recently, detailed bioinformatic analyses have been restricted largely to specialized 
laboratories with substantial computer and software capacities. However, the introduction of new integrated bioinformatic systems, such as Bio-cloud (http://cloud.genomics.cn) and Artemis (http://www.sanger.ac.uk/resources/software/ artemis/), for the de novo assembly and annotation of NGS sequence data could represent a turning point for 'omic' research (Santhoshkumar et al., 2012; Cantacessi et al., 2012). The annotation of proteins inferred from the genomic and transcriptomic datasets is usually performed by assigning predicted biological functions based on comparison with existing information available for $C$. elegans and for other organisms in public databases (e.g. WormBase, http://www.wormbase.org; InterPro, http:// www.ebi.ac.uk/interpro/; Gene Ontology, http://www.geneontology.org/; OrthoMCL, http://www.orthomcl.org/; BRENDA, http://www.brenda-enzymes.org/). Using this approach, predictions for key groups of molecules, linked to the physiology of the nervous system, the formation of the cuticle, proteases and protease inhibitors, and protein kinases and phosphatases etc. have been made in relation to their function and essential roles in biological processes (Cantacessi et al., 2012; Cantacessi et al., 2012; Ballereau et al., 2013).

\section{Transcriptomics}

Transcriptomics is the genome-wide identification and quantification of RNA species such as mRNAs, non-coding RNAs and small RNAs in healthy state and disease state. in response to external stimuli. Highthroughput sequencing of RNA has become the standard assay for measuring gene expression, and numerous studies conducting "RNA-Seq" experiments in parasites have now been performed and deposited in the sequence archives. Investigations of the transcriptome of parasites using different approaches is gradually leading to a better understanding of the biochemical and molecular processes involved in parasite development, reproduction and interactions with their host/s (Cantacessi et al., 2012; Cantacessi et al., 2012). In NGS, particularly the 454 platform was used for the de novo sequencing of the transcriptomes of important parasites such as trematodes Clonorchis sinensis (Young et al., 2010), F. hepatica (Young et al., 2010), F. gigantica (Zhang et al., 2017), Paramphistomum cervi (Choudhary et al., 2015), T. colubriformis, ( $\mathrm{Ku}$ and Roukos, 2013), Ixodes ricinus (Schwarz et al., 2013), Haemaphysalis flava (Xu et al., 2015), Rhipicephalus appendiculatus (De Castro et al., 2016), Dermanyssus gallinae (Schicht et al., 2014), Tritrichomonas foetus (Morin-Adeline et al., 2015) and Neospora caninum (Ramaprasad et al., 2015).

\section{Proteomics}

The study of proteins present in a tissue or fluid (the proteome). Generally, Proteome refers to the set of proteins in the cell or an organism and vary depending on the stimuli. Recently, proteomic studies generating data and awakening interest in using proteomics and the complementary bioinformatics tools to address problems of veterinary pathogenesis. Since, its provides necessary tools for large-scale experimental analysis of the molecules generating during stimuli and provide data on relevant protein sets from pathogen as well as from the host. Mass spectrometry is widely used proteomic toolfor identification and diagnosis of parasitic infections. Mass spectrometry (MS) relies on the deflection of charged atoms by magnetic fields in a vacuum to measure their mass/charge $(\mathrm{m} / \mathrm{z})$ ratio. A typical experiment follows five steps: (1) introduction of the sample, (2) ionization of its particles, (3) acceleration, (4) deflection proportional to the 
mass and charge of the ion, and (5) detection. A mass spectrometer consists of an ion source, a mass analyser that measures the mass-to-charge ratio $(\mathrm{m} / \mathrm{z})$ of the ionized analytes, and a detector that registers the number of ions at each $\mathrm{m} / \mathrm{z}$ value. Currently, four basic types of mass analyser are used in proteomic research, Viz., a. ion trap, b. timeof-flight (TOF), c. quadrupole and d. Fourier transform ion cyclotron analysers. They are very different in design and performance, itsown strength and weakness (Aebersold and Mann, 2003). In recent years, the identification of novel biomarkers in parasite diagnostics has relied on the use of mass spectrometry (MS) platforms. Such instruments include matrix-assisted laser desorption ionization time-of-flight mass spectrometry (MALDI-TOF MS), surfaceenhanced laser desorption ionization time of flight mass spectrometry (SELDI-TOF MS), liquid chromatography combined with MS (LC-MS-MS), isotope-coded affinity tags (ICAT), and isotope tags for relative and absolute quantification (iTRAQ) (Ndao, 2009). Most studies published on parasitic diseases have all focused on the use of MALDI-TOF MS and SELDI-TOF MS. Pathogenesis of gastrointestinal nematode infection was recently studied by quantitatively investigating the expression of proteins by abomasal mucosa of resistant and susceptible sheep breed after experimental Haemonchus contortus infection (Nagaraj et al., 2012).

\section{MALDI-TOF MS}

This is a mass spectrometry with soft ionization technique used for the analysis of biomolecules such as DNA, protein, peptides and sugar or polymers. This method is having three steps such as 1 . The sample is mixed with suitable matrix and applied to a metal plate. 2, a pulsed laser irradiates a sample triggering desorption of matrix material and 3 .
Ionization of analyte molecules. The typical detector used with MALDI is the time of flight mass detector (TOF-MS). Where, the ions are accelerated by an electric field, resulting in ions of the same strength to have the same kinetic energy. The time it takes for each ion to tranverse the flight tube and arrive at the detector is based on its mass-to-charge ratio; therefore the heavier ions have shorter arrival times compared to lighter ions (Hillenkamp et al., 1991; Lewis et al., 2000). MALDI-TOF MS has emerged as an alternative technique for the identification of a number of arthropods such as Culicoides (Kaufmann et al., 2012), mosquitoes (Suarez et al., 2011) and ticks (Karger et al., 2012).

\section{SELDI-TOF MS}

SELDI-TOF is a version of MALDI-TOF mass spectrometry where, the sample matrix protein chip, play an active role in sample purification as well as the desorption/ionization step. This technology is based on the separation of proteins using their chemical and physical characteristics (i.e., hydrophobic, hydrophilic, acidic, basic, metal affinity) by performing a chromatographic separation of the sample to be analyzed. SELDI-TOF has three major components such as: the protein chip arrays, the mass analyzer, and the data analysis software (Merchant, 2000; Tarawneh and Bencharit, 2009). SELDI technique has been applied to the study of serum biomarkers of parasitic diseases such as human African trypanosomosis (Agranoff et al., 2005), fasciolosis (Rioux et al., 2008) and cysticercosis (Deckers et al., 2008).

The gold standard test for parasitic diagnosis is microscopy whereas, several limitations including sensitivity. Presently, new technologies have emerged to address some of these limitations with increased 
advantages. In recent years, research area is shifting alternative methods to improve the diagnosis of parasitic diseases. The molecular-based approaches and proteomics using mass spectrometry are much higher through put technologies used for parasitic diagnosis. Present communication summarizes the information about various detection methods of parasitic infections of livestock and humans.

\section{References}

Abbasi, I., King, C. H., Muchiri, E. M., and Hamburger, J. 2010. Detection of Schistosoma mansoni and Schistosoma haematobium DNA by loop-mediated isothermal amplification: identification of infected snails from early prepatency. Am. J. Trop. Med. Hyg., 83(2):427-432.

Aebersold, R., and Mann, M. 2003. Mass spectrometry-based proteomics. Nature, 422(6928): 198.

Agranoff, D., Stich, A., Abel, P., and Krishna, S. 2005. Proteomic fingerprinting for the diagnosis of human African trypanosomiasis. Trends Parasitol., 21(4):154-7.

Ajzenberg, D., Collinet, F., Mercier, A., Vignoles, P., and Dardé, M. L. 2010. Genotyping of Toxoplasma gondii isolates with 15 microsatellite markers in a single multiplex PCR assay. J. Clin. Microbiol., 48(12):4641-5.

Alba, A., Vázquez, A. A., Hernández, H., Sánchez, J., Marcet, R., Figueredo, M. et al., 2015. A multiplex PCR for the detection of Fasciola hepatica in the intermediate snail host Galba cubensis. Vet. Parasitol., 211(3-4):195-200.

Alhassan, A., Thekisoe, O. M, Yokoyama, N., Inoue, N., Motloang, M. Y., Mbati, P. A. et al., 2007. Development of loopmediated isothermal amplification (LAMP) method for diagnosis of equine piroplasmosis. Vet. Parasitol., 143(2):155-60.

Al-Hosary, A. A., Ahmed, J., Nordengrahn, A., and Merza, M. 2015. Assessment of the First Commercial ELISA Kit for the Diagnosis of Theileria annulata. J. Parasitol. Res., 1-4.

Al-Tarawneh, S. K., and Bencharit, S. 2009. Applications of surface-enhanced laser desorption/ionization time-of-flight (SELDI-TOF) mass spectrometry in defining salivary proteomic profiles. Open. Dent. J., 3:74.

Aonuma, H., Yoshimura, A., Perera, N., Shinzawa, N., Bando, H., Oshiro, S. et al., 2009. Loop-mediated isothermal amplification applied to filarial parasites detection in the mosquito vectors: Dirofilaria immitis as a study model. Parasit. Vectors, 2(1):15.

Ballereau, S., Glaab, E., Kolodkin, A., Chaiboonchoe, A., Biryukov, M., Vlassis, N. et al., 2013. Functional genomics, proteomics, metabolomics and bioinformatics for systems biology. BMC. Syst. Biol., 3-41.

Barkway, C. P., Pocock, R. L., Vrba, V., and Blake, D. P. 2015. Loop mediated isothermal amplification (LAMP) assays for the species-specific detection of Eimeria that infect chickens. J. Vis. Exp., 20:96.

Belák, S., Karlsson, O. E., Leijon, M., and Granberg, F. 2013. High-throughput sequencing in veterinary infection biology and diagnostics. Rev. Sci. Tech., 32:893-915.

Bhaskar, S., Singh, S., and Sharma, M. 1996. A single-step immunochromatographic test for the detection of Entamoeba histolytica antigen in stool samples. J. Immunol. Methods, 196(2):193-8.

Birhanu, H., Rogé, S., Simon, T., Baelmans, R., Gebrehiwot, T., Goddeeris, B. M. et al., 2015. Surra Sero K-SeT, a new immunochromatographic test for 
serodiagnosis of Trypanosoma evansi infection in domestic animals. Vet. Parasitol., 211(3-4):153-7.

Blears, M. J., Pokorny, N. J., Carreno, R. A., Chen, S., De Grandis, S. A., Lee, H. et al., 2000. DNA fingerprinting of Cryptosporidium parvum isolates using amplified fragment length polymorphism (AFLP). J. Parasitol., 86(4):838-41.

Brenner, S. 1974. The genetics of Caenorhabditis elegans. Genetics, 77:71-94.

Burbelo, P. D., Ramanathan, R., Klion, A. D., Iadarola, M. J., and Nutman, T. B. 2008. Rapid, novel, specific, highthroughput assay for diagnosis of Loa loa infection. J. Clin. Microbiol., 46(7): 2298-304.

Cantacessi, C., Campbell, B. E., Jex, A. R., Young, N. D., Hall, R. S., Ranganathan, S. et al., 2012. Bioinformatics meets parasitology. Parasite. Immunol., 34(5):265-75.

Cantacessi, C., Campbell, B. E., and Gasser, R. B. 2012. Key strongylid nematodes of animals-Impact of next-generation transcriptomics on systems biology and biotechnology. Biotechnol. Adv., 30(3):469-88.

Cantacessi, C., Campbell, B. E., Young, N. D., Jex, A. R., Hall, R. S., Presidente, P. J. et al., 2010. Differences in transcription between free-living and $\mathrm{CO}$ 2-activated third-stage larvae of Haemonchus contortus. BMC. Genomics, 11(1):266.

Cantacessi, C., Mitreva, M., Campbell, B. E., Hall, R. S., Young, N. D., Jex, A. R. et $a l ., 2010$. First transcriptomic analysis of the economically important parasitic nematode, Trichostrongylus colubriformis, using a next-generation sequencing approach. Infect. Genet. Evol., 10(8):1199-207.
Cantacessi, C., Mitreva, M., Jex, A. R., Young, N. D., Campbell, B. E., Hall, R. S. et al., 2010. Massively parallel sequencing and analysis of the Necator americanus transcriptome. PLOS. Negl. Trop. Dis., 4(5):e684.

Chen, X. S., Collins, L. J., Biggs, P. J., and Penny, D. 2009. High throughput genome-wide survey of small RNAs from the parasitic protists Giardia intestinalis and Trichomonas vaginalis. Genome. Biol. Evol., 1:165-75.

Choudhary, V., Garg, S., Chourasia, R., Hasnani, J. J., Patel, P.V., Shah, T. M. et al., 2015. Transcriptome analysis of the adult rumen fluke Paramphistomum cervi following next generation sequencing. Gene, 570(1):64-70.

Cruz-Flores, M. J., Bata, M., Co, B., Claveria, F. G., Verdida, R., Xuan, X. et al., 2010. Immunochromatographic assay of Babesia caballi and Babesia equi Laveran 1901 (Theileria equi Mehlhorn and Schein, 1998) (Phylum Apicomplexa) infection in Philippine horses correlated with parasite detection in blood smears. Vet. Arhiv., 80(6):71522.

De Carvalho, R. F., Ribeiro, I. F., MirandaVilela, A. L., de Souza Filho, J., and Martins, O. P, et al., 2013. Leishmanicidal activity of amphotericin B encapsulated in PLGA-DMSA nanoparticles to treat cutaneous leishmaniasis in C57BL/6 mice. Exp. Parasitol., 135(2):217-22.

De Castro, J. J. 1997. Sustainable tick and tickborne disease control in livestock improvement in developing countries. Vet. Parasitol., 71(2-3):77-97.

De Castro, M. H., De Klerk, D., Pienaar, R., Latif, A. A., Rees, D. J., and Mans, B. J. 2016. De novo assembly and annotation of the salivary gland transcriptome of Rhipicephalus appendiculatus male and 
female ticks during blood feeding. Ticks. Tick. Borne. Dis., 7(4):536-48.

Deckers, N., Dorny, P., Kanobana, K., Vercruysse, J., Gonzalez, A. E., Ward, B. et al., 2008. Use of ProteinChip technology for identifying biomarkers of parasitic diseases: the example of porcine cysticercosis (Taenia solium). Exp. Parasitol., 120(4):320-9.

Deepak, S., and Singla, L.D. 2016. Immunodiagnosis Tools for Parasitic Diseases. J. Microb. Biochem. Technol., 8:514-8.

Devendra C. 1995. Global Agenda for Livestock Reasearch: Proceedings of a consultation. ILRI, Nairobi, Kenya, Pp. 41-48.

Duncan, R. 2004. DNA microarray analysis of protozoan parasite gene expression: outcomes correlate with mechanisms of regulation. Trends. Parasitol., 20(5):211-5.

Gadelhaq, S. M., Arafa, W. M., and Aboelhadid, S. M. 2015. Molecular characterization of Eimeria species naturally infecting egyptian baldi chickens. Iran. J. Parasitol., 10(1):87.

Gasser, R. B. 2006. Molecular tools advances, opportunities and prospects. Vet. Parasitol., 136(2):69-89.

Gasser, R. B. 2013. A perfect time to harness advanced molecular technologies to explore the fundamental biology of Toxocara species. Vet Parasitol., 193(4):353-64.

Guan, G., Chauvin, A., Luo, J., Inoue, N., Moreau, E., Liu, Z. et al., 2008. The development and evaluation of a loopmediated isothermal amplification (LAMP) method for detection of Babesia spp. infective to sheep and goats in China. Ex. Parasitol., 120(1):39-44.

Guswanto, A., Allamanda, P., Mariamah, E. S., Munkjargal, T., Tuvshintulga, B., Takemae, H. et al., 2017. Evaluation of immunochromatographic test (ICT) strips for the serological detection of Babesia bovis and Babesia bigemina infection in cattle from Western Java, Indonesia. Vet. Parasitol., 239:76-9.

Hillenkamp, F., Karas, M., Beavis, R. C., and Chait, B. T. 1991. Matrix-assisted laser desorption/ionization mass spectrometry of biopolymers. Anal. Chem., 63(24):1193A-203A.

Huang, X., Xuan, X., Xu, L., Zhang, S., Yokoyama, N., Suzuki, N. et al., 2004. Development of an immunochromatographic test with recombinant EMA-2 for the rapid detection of antibodies against Babesia equi in horses. J. Clin. Microbiol., 42(1):359-61.

Jaswal, H., Bal, M. S., Singla, L. D., Amrita, K. P., Mukhopadhyay, J. P., and Juyal, P. D. 2014. Application of msp1 $\beta$ PCR and 16S rRNA semi nested PCR-RFLP for detection of persistent anaplasmosis in tick infested cattle. Int. J. Adv. Res., 2(8):188-96.

Jia, H., Liao, M., Lee, E., Nishikawa, Y., Inokuma, H., Ikadai, H. et al., 2007. Development of an immunochromatographic test with recombinant $\mathrm{BgSA} 1$ for the diagnosis of Babesia gibsoni infection in dogs. Parasitol. Res., 100(6):1381-4.

Karger, A., Kampen, H., Bettin, B., Dautel, H., Ziller, M. et al., 2012. Species determination and characterization of developmental stages of ticks by wholeanimal matrix-assisted laser desorption/ionization mass spectrometry. Ticks. Tick. Borne. Dis., 3: 78-89.

Kaufmann, C., Schaffner, F., Ziegler, D., Pfluger, V., and Mathis, A. 2012. Identification of field-caught Culicoides biting midges using matrix-assisted laser desorption/ionization time of flight 
mass spectrometry. Parasitology, 139: 248-258.

Kim, C. M., Blanco, L. B., Alhassan, A., Iseki, H., Yokoyama, N., Xuan, X et al., 2008. Development of a rapid immunochromatographic test for simultaneous serodiagnosis of bovine babesioses caused by Babesia bovis and Babesia bigemina. Am. J. Trop. Med. Hyg., 78(1):117-21.

$\mathrm{Ku}, \mathrm{C}$. S., and Roukos, D, H. 2013. From next-generation sequencing to nanopore sequencing technology: paving the way to personalized genomic medicine. Expert. Rev. Med. Devices., 10(1):1-6.

$\mathrm{Ku}, \mathrm{C}$. S., and Roukos, D. H. 2013. From next-generation sequencing to nanopore sequencing technology: paving the way to personalized genomic medicine. Expert. Rev. Med. Devices., 10(1):1-6.

Kumar, A., Boggula, V. R., Misra, P., Sundar, S., Shasany, A. K., and Dube, A. 2010. Amplified fragment length polymorphism (AFLP) analysis is useful for distinguishing Leishmania species of visceral and cutaneous forms. Acta. Tropica., 113(2):202-6.

Lewis, J. K., Wei, J., and Siuzdak, G. 2000. Matrix-Assisted Laser Desorption/Ionization Mass Spectrometry in Peptide and Protein Analysis. Encyclopedia of Analytical Chemistry. 2000.

Lin, R. Q., Liu, G. H., Hu, M., Song, H. Q., Wu, X. Y., Li, M. W. et al., 2012. Oesophagostomum dentatum and Oesophagostomum quadrispinulatum: characterization of the complete mitochondrial genome sequences of the two pig nodule worms. Exp. Parasitol., 131(1):1-7.

Livestock census 2012. 19 th $^{\text {th }}$ All India Livestock Census, Dept. of Animal Husbandry \& Dairying Ministry of Agriculture, Government of India.
Lofty, W., Brant, S., Ashmawy, K., Devkota, R., Mkojie, G. M., and Loker, E. S. 2010. A molecular approach $\mathrm{h}$ for identification of Paramphistomomes form Africa and Asia. J. Vet. Parasitol., 174:234-240.

Merchant, M., and Weinberger, S. R. 2000. Recent advancements in surface- enhanced laser desorption/ionization- time of flight- mass spectrometry. Electrophoresis, 21(6):1164-77.

Minjauw, B., and McLeod, A. 2003. Tickborne diseases and poverty: The impact of ticks and tick-borne diseases on the livelihood of small-scale and marginal livestock owners in India and eastern and southern Africa. DFID Animal Health Programme, Centre for Tropical Veterinary Medicine, University of Edinburgh, U.K. Pp. 116.

Molloy, S. F., Smith, H. V., Kirwan, P., Nichols, R. A., Asaolu, S. O., Connelly, L. et al., 2010. Identification of a high diversity of Cryptosporidium species genotypes and subtypes in a pediatric population in Nigeria. Am. J. Trop. Med. Hyg., 82(4):608-13.

Montenegro-James, S., and James, M. A. 1998. Bovine babesiosis: Recent advances in diagnosis-Review article. J.Vet. Parasitol., 12:67-71.

Morin-Adeline, V., Mueller, K., Conesa, A., and Šlapeta, J. 2015. Comparative RNA-seq analysis of the Tritrichomonas foetus PIG30/1 isolate from pigs reveals close association with Tritrichomonas foetus BP-4 isolate 'bovine genotype'. Vet. Parasitol., 212(3-4):111-7.

Nagaraj, S. H., Harsha, H. C., Reverter, A., Colgrave, M. L., Sharma, R., Andronicos, N. et al., 2012. Proteomic analysis of the abomasal mucosal response following infection by the nematode, Haemonchus contortus, in 
genetically resistant and susceptible sheep. J. Proteomics., 75(7):2141-52.

Ndao, M. 2009. Diagnosis of parasitic diseases: old and new approaches. Interdiscip. Perspect. Infect. Dis., 15.

Niazi, A., Jorjani, O. N., Nikbakht, H., and Gill, P. 2013. A nanodiagnostic colorimetric assay for $18 \mathrm{~S}$ rRNA of Leishmania pathogens using nucleic acid sequence-based amplification and gold nanorods. Mol. Diagn. Ther., 17(6):363-70.

OIE. 2008. Manual of diagnostic tests and vaccines for terrestrial animals. Office international des epizooties, paris, France, 1092-106.

Perinoto, A. C., Maki, R. M., Colhone, M. C., Santos, F. R., Migliaccio, V., Daghastanli, K. R. et al., 2010. Biosensors for efficient diagnosis of leishmaniasis: innovations in bioanalytics for a neglected disease. Anal. Chem., 82(23):9763-8.

Pillai, D. R., and Kain, K. C. 1999. Immunochromatographic Strip-Based Detection of Entamoeba histolytica E. dispar and Giardia lamblia Coproantigen. J. Clin. Microbiol., 37(9):3017-9.

Qablan, M. A., Boyer, F., Miquel, C., D'Amico, G., Mihalca, A. D., Pompanon, D. et al., 2014. Next generation sequencing as a novel tool for diagnostics of apicomplexan pathogen in ticks and mammalian hosts. Parasit. Vectors. 7(1):O13.

Quan, J. H., Kim, T. Y., Choi, I. U., and Lee, Y. H. 2008. Genotyping of a Korean isolate of Toxoplasma gondii by multilocus PCR-RFLP and microsatellite analysis. Korean. J. Parasitol., 46(2): 105.

Ramanathan, R., Burbelo, P. D., Groot, S., Iadarola, M. J., Neva, F.A., and Nutman, T.B. 2008. A luciferase immunoprecipitation systems assay enhances the sensitivity and specificity of diagnosis of Strongyloides stercoralis infection. J. Infect. Dis., 2008; 198 (3): 444-51.

Ramaprasad, A., Mourier, T., Naeem, R., Malas, T. B., Moussa, E., Panigrahi, A. et al., 2015. Comprehensive evaluation of Toxoplasma gondii VEG and Neospora caninum LIV genomes with tachyzoite stage transcriptome and proteome defines novel transcript features. PloS. One, 10(4):e0124473.

Ranjan, K., Minakshi, P., and Prasad, G. 2015. Application of molecular and serological diagnostics in veterinary parasitology. J. Adv. Parasitol., 2(4):8099.

Reslova, N., Michna, V., Kasny, M., Mikel, P., Kralik, P. 2017. xMAP Technology: Applications in Detection of Pathogens. Front. Microbiol., 8:55.

Ricciardi, A., and Ndao, M. 2015. Diagnosis of parasitic infections: what's going on? J. Biomol. Screen., 20(1):6-21.

Rioux, M. C., Carmona, C., Acosta, D., Ward, B., Ndao, M., Gibbs, B. F. et al., 2008. Discovery and validation of serum biomarkers expressed over the first twelve weeks of Fasciola hepatica infection in sheep. Int. J. Parasitol., 38(1):123-36.

Rogé, S., Baelmans, R., Claes, F., Lejon, V., Guisez, Y., Jacquet, D., et al., 2014. Development of a latex agglutination test with recombinant variant surface glycoprotein for serodiagnosis of surra. Vet. Parasitol., 205(3-4): 460-5.

Santhoshkumar, T., Rahuman, A. A., Bagavan, A., Marimuthu, S., Jayaseelan, C., Kirthi, A. V. et al., 2012. Evaluation of stem aqueous extract and synthesized silver nanoparticles using Cissus quadrangularis against Hippobosca maculata and Rhipicephalus 
(Boophilus) microplus. Exp. Parasitol., 132(2):156-65.

Schicht, S., Qi, W., Poveda, L., and Strube, C. 2014. Whole transcriptome analysis of the poultry red mite Dermanyssus gallinae (De Geer, 1778). Parasitol., 141(3):336-46.

Schwarz, A., von Reumont, B. M., Erhart, J., Chagas, A. C., Ribeiro, J. M., and Kotsyfakis, M. 2013. De novo Ixodes ricinus salivary gland transcriptome analysis using two next-generation sequencing methodologies. FASEB, J., 27(12):4745-56.

Sengupta, P. P. 2004. Complement fixation test based COFEB- kit for the diagnosis of Babesia equi infection in equines (patent application no. 36/DEL/2001, dt. 19.01.2001) Patent related to COFEB kit. (56/DEL/2004).

Skotarczak, B., and Sawczuk, M. 2008. Molecular diagnostics of Babesia and Theileria. Przegl. Epidemiol., 62:100-8.

Songa, E. B., and Hamers, R. 1988. A card agglutination test (CATT) for veterinary use based on an early VAT RoTat $1 / 2$ of Trypanosoma evansi. Ann. Soc. Belg. Med. Trop., 68(3): 233-240.

Suarez, E., Nguyen, H. P., Ortiz, I. P., Lee, K. J., Kim, S. B. et al., 2011 Matrixassisted laser desorption/ionizationmass spectrometry of cuticular lipid profiles can differentiate sex, age, and mating status of Anopheles gambiae mosquitoes. Anal. Chim. Acta., 706: 157-163.

Tavares, R. G., Staggemeier, R., Borges, A. L., Rodrigues, M. T., Castelan, L.A, Vasconcelos, J. et al., 2011. Molecular techniques for the study and diagnosis of parasite infection. J. Venom. Anim. Toxins. Incl. Trop. Dis., 17(3):239-48.

Temperley, N. D., Webster, L. M., Adam, A., Keller, L. F., and Johnson, P.C. 2009. Cross-species utility of microsatellite markers in Trichostrongyloid nematodes. J. Parasitol., 95(2):487-9.

Verdida, R. A., Xuan, X., Fukumoto, S., Huang, X., Zhou, J., Igarashi, I. et al., 2005. Development of a practical immunochromatographic test with recombinant $\mathrm{P}_{50}$ for the diagnosis of Babesia gibsoni infection in dogs. Parasitology., 131(6):769-74.

Verma, R., Sharma, D. K., Gururaj, K., Paul, S., Banerjee, P. S., and Tiwari, J. 2017. Molecular epidemiology and point mutations in ITS1 and 18S rDNA genes of Eimeria ninakohlyakimovae and $E$. christenseni isolated from Indian goats. Vet. Parasitol. Reg. Stud. Rep., 9:51-62.

Vidic, J., Manzano, M., Chang, C. M., and Jaffrezic-Renault, N. 2017. Advanced biosensors for detection of pathogens related to livestock and poultry. Vet. Res. 48(1): 11.

Waknine-Grinberg, J. H., Even-Chen, S., Avichzer, J., Turjeman, K., BenturaMarciano, A., Haynes, R. K., Weiss, L. et al., 2013. Glucocorticosteroids in nano-sterically stabilized liposomes are efficacious for elimination of the acute symptoms of experimental cerebral malaria. PLoS. One., 8(8):72722.

Wang, J. 2005. Nanomaterial-based electrochemical biosensors. Analyst., 130(4):421-6.

Wang, X. W., Luan, J. B., Li, J. M., Bao, Y. Y., Zhang, C. X., and Liu, S. S. 2010. De novo characterization of a whitefly transcriptome and analysis of its gene expression during development. BMC. Genomics., 11(1):400.

Xu, X. L., Cheng, T. Y., Yang, H., Yan, F., and Yang, Y. 2015. De novo sequencing, assembly and analysis of salivary gland transcriptome of Haemaphysalis flava and identification of sialoprotein genes. Infect. Genet. Evol., 32:135-42. 
Yadav. S. C. 2018. Lateral flow immunoassay; a new approach for diagnosis of Trypanosoma evansi infection in equines, NCVP conference 12-14 February, 88-94.

Young, N. D., Campbell, B. E., Hall, R. S., Jex, A. R., Cantacessi, C., Laha, T. et al., 2010. Unlocking the transcriptomes of two carcinogenic parasites, Clonorchis sinensis and Opisthorchis viverrini. PLoS. Negl. Trop. Dis., 4(6):e719.

Young, N. D., Hall, R. S., Jex, A. R., Cantacessi, C., and Gasser, R. B. 2010. Elucidating the transcriptome of Fasciola hepatica - a key to fundamental and biotechnological discoveries for a neglected parasite. Biotechnol. Adv., 28(2):222-31.

Zaeemi, M., Haddadzadeh, H., Khazraiinia, P., Kazemi, B., and Bandehpour, M.
2011. Identification of different Theileria species (Theileria lestoquardi, Theileria ovis, and Theileria annulata) in naturally infected sheep using nested PCR-RFLP. Parasitol. Res., 108(4):837-43.

Zahedi, A., Gofton, A. W., Jian, F., Paparini, A., Oskam, C., Ball, A. et al., 2017. Next Generation Sequencing uncovers within-host differences in the genetic diversity of Cryptosporidium gp60 subtypes. Int. J. Parasitol., 47(1011):601-7.

Zhang, X. X., Cong, W., Elsheikha, H. M., Liu, G. H., Ma, J. G., Huang, W.Y. et al., 2017. De novo transcriptome sequencing and analysis of the juvenile and adult stages of Fasciola gigantica. Infect. Genet. Evol., 51:33-40.

\section{How to cite this article:}

Rupesh Verma, G. Das, H.V. Manjunathachar and Nirmala Muwel. 2018. Advances in Diagnostics of Parasitic Diseases: Current Trends and Future Prospects. Int.J.Curr.Microbiol.App.Sci. 7(07): 3261-3277. doi: https://doi.org/10.20546/ijcmas.2018.707.380 